\title{
Population Dynamics Of Java Slow Loris Nycticebus javanicus E. Geoffroy, 1812 in Dayeuh Luhur Village, Ganeas Sub-District, Sumedang District, West Java
}

Kevin Triandhika ${ }^{1,2}$, Maya Salsabila ${ }^{1,2}$, Anisa Putri Sukmaningrum ${ }^{1,2}$, Sri Suci Utami Atmoko $^{1,2,3}$

${ }^{1}$ Program Studi Biologi, Fakultas Biologi, Universitas Nasional, Jl. Sawo Manila, Pejaten, Pasar Minggu, Jakarta 12520, Indonesia

2,"LUTUNG" Forum Studi Primata, Universitas Nasional, J1. Sawo Manila, Pejaten, Pasar Minggu, Jakarta 12520, Indonesia

${ }^{3}$ Pusat Riset Primata, Universitas Nasional, Jl. Sawo Manila, Pejaten, Pasar Minggu, Jakarta 12520, Indonesia

*Corresponding author: kevintriandhika@gmail.com

\section{ABSTRACT}

Javan slow loris (Nycticebus javanicus) is the only Strepsirrhine Primate that can be found in Indonesia and one of two nocturnal primates genera that can be found in Indonesia (besides Tarsius spp). Javan slow loris are endemic primate and have high threat of extinction, IUCN (International Union of Nature and natural Resources) determined the conservation status as Critically Endangered, so that more serious conservation efforts are needed. This study aims to determine the distribution and abudance of populations (N.javanicus) in Dayeuhluhur village, Ganeas District, Sumedang, West Java with total study area of 60 hectares. By using Recces method, data collection of direct encounters done at night on three different transect (Nangkod, Balisuk, and Sukarasa) for three different years. The abundance of Javan slow loris in 2015 was 0,216 indv/ha, and decrease in 2017 was 0,133 indv/ha and in 2018 was 0,200 indv/ha. The existence data of primates is important for conservation strategy, especially for endemic and endangered primate management outside conservation areas.

Key words: Dayeuh luhur, Slow loris, density, distribution, Talun.

\section{ABSTRAK}

Kukang jawa (Nycticebus javanicus) merupakan satu-satunya Primata Strepsirrhine yang dapat ditemukan di Indonesia dan salah satu dari dua genera primata nokturnal yang dapat ditemukan di Indonesia (selain Tarsius spp.). Kukang jaw termasuk primata endemik dan memiliki tingkat ancaman kepunahan yang tinggi, di IUCN (International Union of Nature and Natural Resources) menetapkan sebagai primata dengan status konservasi terancam punah sehingga diperlukan upaya konservasi yang lebih serius. Penelitian ini bertujuan untuk mengetahui sebaran dan kelimpahan populasi (N. javanicus) di desa Dayeuh Luhur, Kecamatan Ganeas, Kabupaten Sumedang, Jawa Barat dengan total kawasan studi $60 \mathrm{Ha}$. Dengan metode Recces (Reki) pengambilan data perjumpaan langsung dilakukan malam hari pada tiga jalur (Nangkod, Balisuk dan Sukarasa) 
selama tiga tahun yang berbeda. Kelimpahan individu kukang jawa pada tahun 2015 adalah 0,216 ind/Ha, mengalami penurunan pada tahun 2017 yaitu 0,133 ind/Ha dan pada tahun 2018 adalah $0,200 \mathrm{ind} / \mathrm{Ha}$. Data keberadaan primata ini penting untuk strategi pelestarian, khususnya dalam rangka pengelolaan primata endemik dan terancam punah di luar kawasan konservasi.

Kata kunci: Dayeuh luhur, Slow loris, density, distribution, Talun.

\section{PENDAHULUAN}

Indonesia merupakan salah satu negara yang sangat penting dalam konservasi primata di dunia, karena memiliki keragaman jenis yang tinggi, termasuk diantaranya jenis endemik. Keadaan geografis Indonesia yang berupa kepulauan, mendukung hal tersebut, berdasarkan data The Integrated Taxonomic Information System (ITIS) jumlah dari jenis jenis primata di dunia terdapat sekitar 500 spesies. Sedangkan jumlah spesies primata di Indonesia menempati urutan ketiga setelah Brazil dan Madagaskar.Primata di Indonesia memiliki jumlah 62 spesies dengan sekitar 77 taksa. Jumlah tersebut termasuk jenis primata yang dilindungi dan juga primata endemik [1].

Primata adalah kelompok yang penting dalam menjaga ekosistem karena peran pentingnya dalam dinamika ekologi, sebagai indikator kesehatan ekosistem, dan nilai penting baik secara lokal ataupun internasional sebagai prioritas konservasi [2]. Oleh karena itu perlu sekali memahami karakteristik ekologi dan prasyaratnya dari tingkat individu, populasi hingga ke tingkat komunitas. Pulau Jawa, khususnya Jawa Barat adalah habitat alami dari 5 jenis primata [3] dan 3 jenis di antaranya termasuk dalam status terancam punah termasuk jenis Kukang [4].

Kukang (Nycticebus spp.) secara umum tersebar di seluruh Asia dan mengalami banyak perubahan klasifikasi [4]. Enam dari marga Nycticebus hidup di Indonesia, yaitu Nycticebus javanicus (endemik di Pulau Jawa), Nycticebus coucang (di Pulau Sumatra dan sekitarnya), dan di Pulau Kalimantan terdapat Nycticebus bancanus, Nycticebus borneanus, Nycticebus menagensis dan Nycticebus kayan [5] (Gambar 1).

Kukang adalah primata nocturnal yang hidup secara arboreal, memiliki ibu jari berseberangan dengan keempat jari lainnya, bergerak lamban dengan sistem lokomosi quadrupedal serta berpindah tempat dengan cara meregangkan tubuh. Kukang memiliki sistem metabolisme basal yang rendah, masa kehamilan yang lama, kelahiran bayi dengan berat yang ringan, masa menyusui yang lama, dan adanya perilaku induk meletakkan bayinya, terutama saat mencari makan [6]. Kukang jawa pada awalnya merupakan subspesies dari $N$. coucang, dan kemudian sebagian besar ahli taksonomi mengelompokkan menjadi jenis terpisah [6]. Ciri morfologi yang memisahkan dengan jenis kukang lainnya adalah pola garpu pada bagian wajah yang jelas dan memiliki bercak rambut warna putih pada bagian leher [6] (Gambar 2).

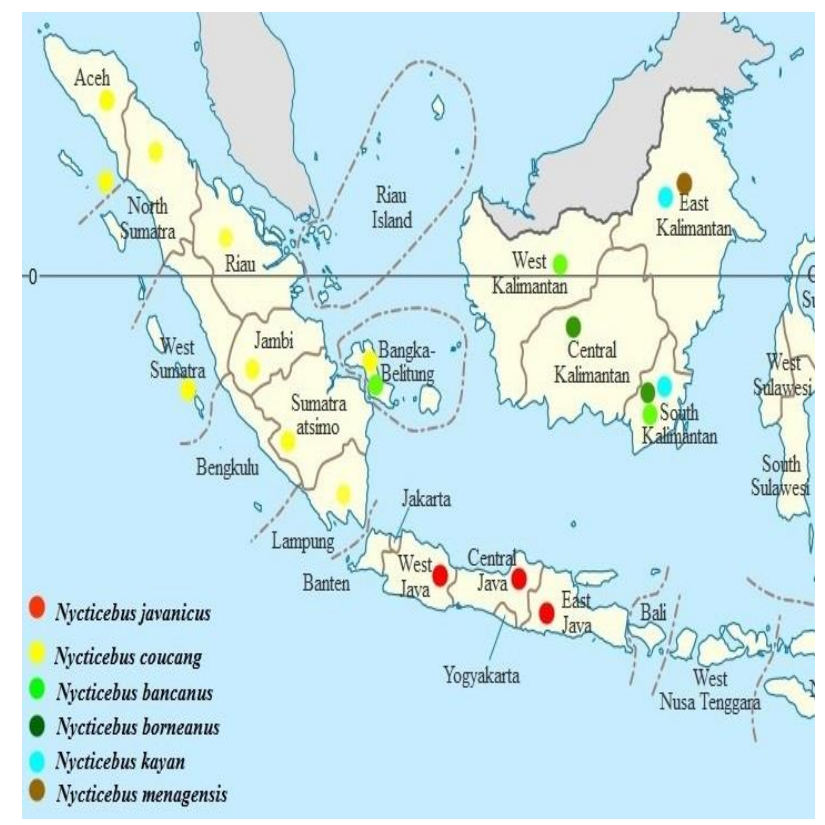

Gambar 1. Peta penyebaran kukang di Indonesia [5]

Endemisitas dan ancaman kepunahan di tingkat spesies memerlukan upaya konservasi yang lebih serius. Oleh karena itu status konservasi kukang jawa berubah. IUCN telah mengubah status konservasi yang sebelumnya Low risk (Kurang terancam) menjadi terancam punah [4]. Status ini diperkuat oleh daftar yang dikeluarkan oleh CITES yang mengubah status kukang jawa dari Appendiks 2 menjadi Appendiks I [7]. Flora dan fauna yang 
termasuk dalam Apendiks I merupakan flora fauna yang jumlahnya sudah sangat sedikit dan memiliki kecenderungan untuk punah. Oleh sebab itu perdagangan kukang jawa baik hidup ataupun mati, sama sekali tidak diperbolehkan untuk kepentingan komersial [8].

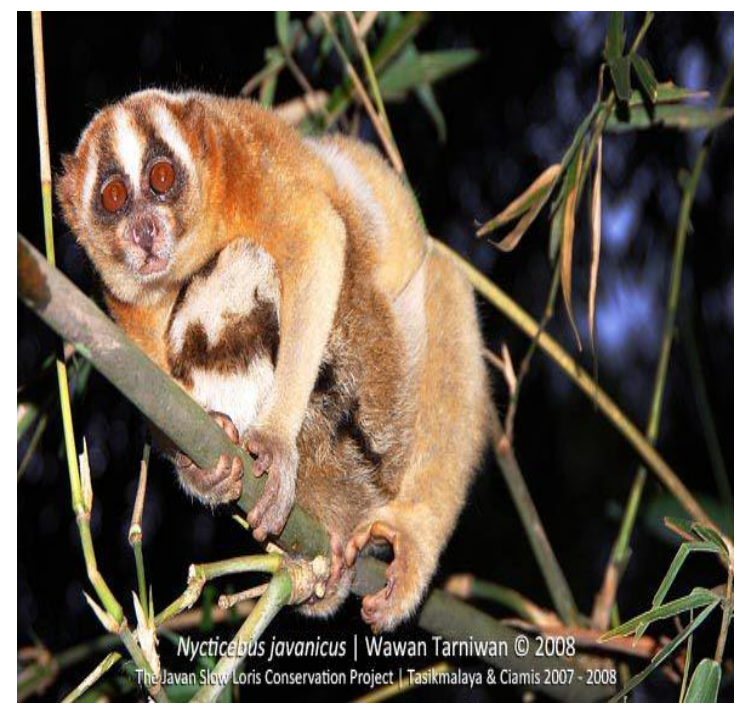

Gambar 2. Ibu dan anak kukang jawa (Nycticebus javanicus) (Sumber: Tarmiwan 2008).

Di alam, kukang jawa dapat ditemukan hidup di hutan primer, hutan sekunder, dan hutan bambu salah satu sebarannya dapat dijumpai di Jawa Barat [9]. Primata ini juga dapat ditemui di luar kawasan konservasi berupa talun atau hutan kebun [10]. Talun adalah hutan buatan berupa kebun pepohonan yang terdiri atas beragam jenis pohon bernilai ekonomis dan tanaman tahunan yang membentuk struktur multistrata [11].

Perubahan kuantitas dan kualitas komponen sebuah ekosistem dari waktu ke waktu sangat berpengaruh pada keseimbangan ekosistem. Sementara itu, spesies sebagai komponen terkecil dalam ekosistem mempunyai pengaruh yang besar, dimana spesies dapat menjadi langka atau habitatnya berubah salah satunya akibat terganggu oleh kegiatan manusia. Dinamika populasi dipengaruhi faktor luar (iklim, gangguan manusia) dan faktor internal yang dapat mempengaruhi reproduksi dan ketahanan hidup. Oleh karena itu, penting untuk mengerti latar belakang perubahan populasi dalam suatu area tertentu dan faktor penyebabnya.

Estimasi populasi dan sebaran individu umumnya dilakukan untuk mengetahui distribusi dan populasi primata yang terdapat di dalam kawasan tertentu. Primata dipilih karena memiliki fungsi sebagai indikator kesehatan ekosistem. Berdasarkan latar belakang tersebut studi ini bertujuan untuk mengidentifikasi sebaran dan kepadatan populasi Kukang Jawa di Desa Dayeuh Luhur, Sumedang.

Kawasan hutan di desa Dayeuh Luhur memiliki potensi besar, jenis flora dan fauna serta keindahan alam lainnya yang bermanfaat untuk pengembangan ilmu pengetahuan khususnya dalam bidang konservasi dan ekowisata.

\section{METODE PENELITIAN}

Pengambilan data dilakukan pada beberapa periode yang berbeda selama 3 tahun yaitu, pada tahun 2015 (Januari, Februari, dan April), tahun 2017 (Juli, Agustus, dan Oktober) dan tahun 2018 (Oktober dan November). Lokasi penelitian adalah di Desa Dayeuh Luhur, Kecamatan Ganeas, Kabupaten Sumedang, Jawa Barat.

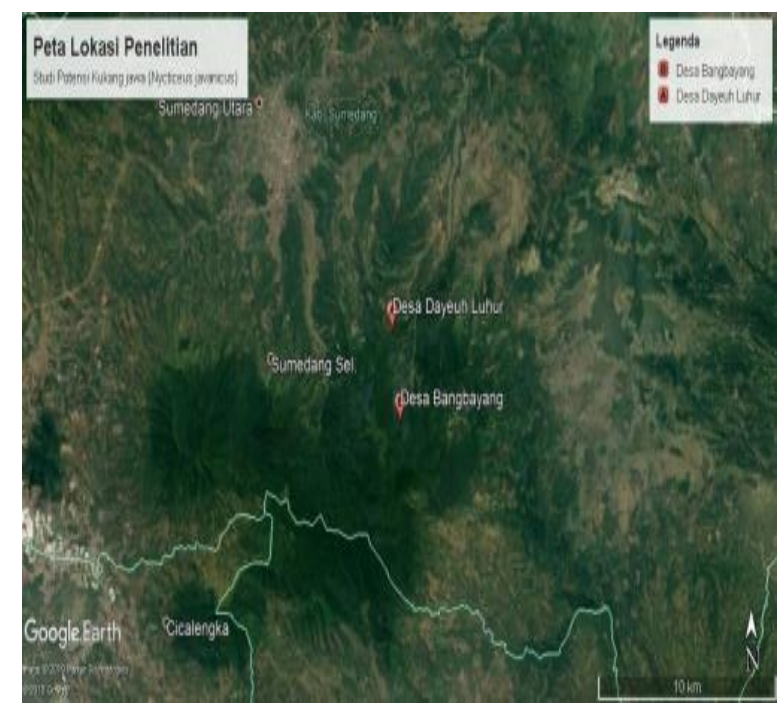

Gambar 3. Peta lokasi penelitian di Desa Dayeuh Luhur.

Estimasi sebaran dan indikasi kelimpahan kukang jawa menggunakan metode line transect dengan modifikasi recces, yaitu pengamatan yang dilakuan pada jalur-jalur yang telah tersedia dan digunakan oleh masyarakat Desa Dayeuh Luhur dengan mencatat Prependicular distance (PPD) yaitu jarak posisi primata dengan jalur transek yang diambil secara tegak lurus, dan Direct distance (DD) yaitu jarak langsung posisi primata dengan jalur transek yang disertai dengan 
pengambilan sudut derajat ke posisi primate [12].

Pencatatan dilakukan pada sore hingga malam hari dan mencatat terhadap semua bentuk perjumpaan dengan primata nokturnal. Beberapa data yang dicatat pada saat pengamatan jumlah individu, kelas umur, jarak interval dari titik awal pengamatan, dan reaksi satwa ketika bertemu pengamat/manusia. Untuk mengetahui sebaran primata nokturnal, pengambilan data dilakukan dengan menandai koordinat pada saat ditemukannya primata di sep anjang maupun di luar jalur pengamatan.

\section{HASIL PENELITIAN}

\section{Populasi Kukang Jawa}

Studi dilakukan pada habitat di luar kawasan konservasi yang dikelola oleh masyarakat. Perbedaan kondisi habitat pada lokasi studi menyebabkan perbedaan populasi individu kukang Jawa pada setiap jalur pengamatan (Tabel 1).

Tabel 1. Jumlah Perjumpaan individu kukang jawa pada lokasi sama dengan tahun yang berbeda.

\begin{tabular}{cccc}
\hline \multicolumn{4}{c}{ Jumlah Individu } \\
\hline Jalur & 2015 & 2017 & 2018 \\
\hline Nangkod & 3 & 5 & 6 \\
Balisuk & 10 & 3 & 1 \\
Sukarasa & $\mathrm{X}$ & $\mathrm{X}$ & 5 \\
\hline Total & 13 & 8 & 12 \\
\hline
\end{tabular}

Hasil penelitian kukang jawa di lokasi lainnya menunjukkan kepadatan individu kukang lebih tinggi pada habitat alami atau hutan dengan sedikit gangguan (talun sempurna), yaitu jalur Nangkod dari pada talun kebun campuran [13]. Tingkat gangguan di talun sempurna lebih rendah daripada talun kebun. Gangguan manusia di habitat talun sempurna berupa kunjungan untuk perawatan talun ataupun pemanenan lebih rendah dibandingkan dengan talun kebun yang terdapat area garapan. Talun sempurna memiliki struktur vegetasi mirip hutan sekunder.

Indikasi kelimpahan individu kukang jawa di Desa Dayeuh Luhur secara keseluruhan disajikan di bawah ini (Tabel 2).
Tabel 2. Kelimpahan individu kukang jawa di Desa Dayeuh Luhur.

\begin{tabular}{cc} 
Tahun & Ind/Ha \\
\hline 2015 & 0,216 \\
2017 & 0,133 \\
2018 & 0,200 \\
\hline
\end{tabular}

Pada tahun 2015, populasi kukang jawa pada lokasi studi memiliki jumlah yang cukup tinggi, namun kondisi ini menurun pada perhitungan dua tahun setelahnya yaitu 2017. Dengan menambah jumlah transek pada saat pengamatan tahun 2018, populasi kukang Jawa memiliki kondisi yang sama dengan tahun pada saat studi ini dimulai. Populasi satwa liar berfluktuasi dari waktu ke waktu mengikuti keadaan fluktuasi lingkungannya. Fluktuasi populasi satwaliar ini dipengaruhi oleh beberapa parameter populasi seperti angka kelahiran, angka kematian, kepadatan populasi, struktur umur dan struktur kelamin (sex ratio) [14].

Estimasi populasi kukang jawa dipengaruhi oleh kepadatan individu kukang dan luas habitat representatif. Dengan luas yang sama, kepadatan individu kukang jawa dapat menjadi gambaran kualitas habitat talun di suatu area. Kepadatan individu kukang jawa yang tinggi secara umum terdapat pada talun yang memiliki struktur vegetasi yang baik, yakni ditunjukkan dari struktur vegetasi yang mirip hutan dan ketersediaan vegetasi untuk tidur dan vegetasi pakan.

Kukang memiliki sebaran yang tidak merata dengan indikasi populasi yang bersifat sementara [4]. Adanya sistem rotasi tanam di talun memungkinkan ketersediaan vegetasi untuk tidur dan sumber pakan sekaligus menjadi indikasi terjadinya perpindahan atau migrasi kukang jawa ke talun lain di sekitarnya. Migrasi dapat terjadi jika talun yang didiami kukang jawa mengalami perubahan, baik perubahan akibat sistem rotasi tanam maupun akibat ancaman perburuan [13].

Pada penelitian ini, kukang jawa lebih sering di temukan pada pohon Aprika (Vernonia amygdalina) dengan kelimpahan relatif sebesar 17,6\% (Tabel 2), karena pohon Aprika merupakan pohon yang besar dengan memiliki kanopi yang lebar memudahkan kukang jawa berpindah dari satu pohon ke pohon lainnya. Adanya rumpun-rumpun 
bambu juga (penyedia sleeping site) di talun dan sekitar kebun yang sengaja dibiarkan penduduk, serta masih terdapatnya pohon aren (Arenga pinnata) (penyedia makanan) yang disadap untuk diambil niranya dan dibuat menjadi gula merah [9].

Populasi satwa liar berfluktuasi dari waktu ke waktu mengikuti keadaan fluktuasi lingkungannya. Fluktuasi populasi satwaliar ini dipengaruhi oleh beberapa parameter populasi seperti angka kelahiran, angka kematian, kepadatan populasi, struktur umur dan struktur kelamin (sex ratio) [14].

Tabel 3. Jenis vegetasi pada saat kukang jawa di temukan

\begin{tabular}{ccc}
\hline Nama Jenis & Nama Lokal & $\mathrm{KR}(\%)$ \\
\hline Vernonia amygdalina & Aprika & 17,6 \\
Arenga pinnata & Aren & 11,8 \\
Hibiscus macrophyllus & Tisuk & 11,8 \\
Bambusa sp & Bambu & 8,8 \\
Albizia procera & Kihiang & 5,9 \\
\hline
\end{tabular}

Penurunan kualitas habitat dapat mempengaruhi stabilitas populasi dan perilaku satwa primata. Berbagai faktor penyebab spesies menjadi langka dan terancam diantaranya disebabkan oleh hilang atau rusaknya bagian vital dari habitatnya, tingginya mortalitas atau rendahnya reproduksi, perubahan iklim, geologi atau evolusi [15].

\section{Sebaran Populasi Kukang Jawa}

Sebaran kukang jawa cenderung mengikuti sebaran habitat talun. Secara umum perjumpaan kukang jawa bersifat tersebar tidak merata. Baik pada waktu aktif maupun tidak aktif (tidur), perjumpaan kukang jawa dapat terjadi di luar habitat talun. Kukang jawa dapat ditemukan tidur di rumpun bambu di tepi jalan pedesaan atau di pekarangan penduduk.

Sebagaimana kondisi talun di hulu sungai Citarum Jawa Barat [16], talun di lokasi penelitian cenderung kecil dan merupakan fragmen dari lansekap lahan. Habitat talun di semua desa terdapat pada area tertentu dari suatu desa. Hal ini berkaitan dengan tata letak tipe guna lahan di desa masing-masing. Pada umumnya pemukiman mengelompok sedangkan lahan pertanian tersebar di seluruh area desa. Secara umum letak talun yang menjadi habitat kukang jawa terletak jauh dari pemukiman. Sebaran talun dapat menjadi indikasi sebaran kukang jawa.

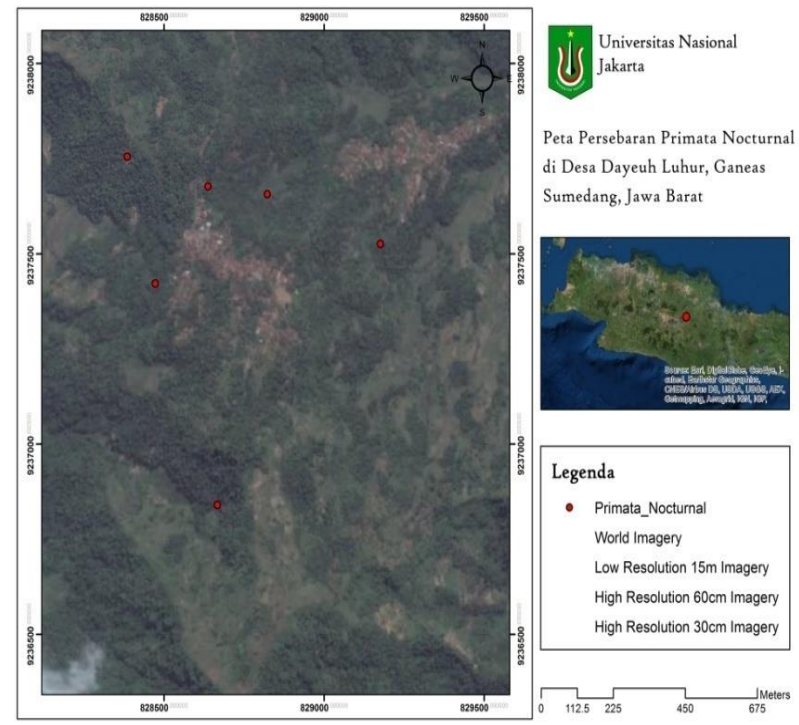

Gambar 4. Peta sebaran perjumpaan kukang jawa di Desa Dayeuh Luhur.

Berdasarkan informasi penduduk, talun Desa Dayeuhluhur sering menjadi area berburu satwa liar seperti burung, bajing, dan musang (Viverridae) menggunakan senapan angin secara berkelompok dan berkala (rutin setiap bulan atau setiap minggu). Adanya perburuan atau kegiatan menembak satwa liar menjadi salah satu penyebab sedikitnya kukang jawa yang dapat ditemukan. Pada saat penelitian tahun 2015 dilakukan, kegiatan perburuan terjadi di Desa Sukamaju dan Sarimanggu. Perburuan di Desa Dayeuhluhur merupakan perburuan secara langsung karena bertujuan mendapatkan hasil buru berupa kukang jawa untuk dijual.

\section{KESIMPULAN}

Sebaran kukang jawa di Desa Dayeuh luhur dijumpai di lahan milik penduduk, tepatnya di talun campuran (jalur Balisuk) dan talun sempurna (jalur nangkod), menjadikannya habitat spesifik kukang jawa. Estimasi kelimpahan kukang jawa di Desa Dayeuh luhur pada tahun 2015 adalah 0,216 ind/Ha, 2017 adalah 0,133 ind/Ha, dan pada tahun 2018 adalah 0,200 ind/Ha dengan luas habitat representatif 60 ha. 


\section{UCAPAN TERIMA KASIH}

Terima kasih kami ucapkan kepada Kepala Desa dan masyarakat Dayeuh Luhur, Fakultas Biologi Universitas Nasional, Tatang Mitra Setia, Sri Suci Utami Atmoko, Imran S. L. Tobing, seluruh anggota aktif dan senior "LUTUNG" Forum Studi Primata yang telah banyak membantu dalam pelaksanaan kegiatan

\section{DAFTAR PUSTAKA}

[1] Tamam, Mh. Badrut. 2017. Daftar primata Indonesia terbaru. https://www.generasibiologi.com/.

Diakses tanggal 14 Juni 2020

[2] Meijaard, E., Sheil, D., Nasi, R., Augeri, D., Rosenbaum, B., Iskandar, D., Setyawati, T., Lammertink, M.,Rachmatika, I., Wong, A., Soehartono, T., Stanley, S. and O'Brien,T. 2005. Life after logging: Reconciling wildlife conservation and production forestry in Indonesian Borneo. CIFOR. Bogor, Indonesia.

[3] Roos, C., Boonratana, R., Supriata, J., Fellowes, J. R., Groves, C. P., Nash, S. D., Rylands, A. B. and Mittermeier, R. 2014. An updated taxonomy and conservation status review of Asian Primates. Asian Primates Journal vol. 4(1): 2-38.

[4] Nekaris, K. A. I., dkk. 2008. Javan Slow Loris (Nycticebus javanicus É. Geoffroy, 1812). dalam: Mittermeier dkk. 2009. editor. Primates in Peril: The World's 25 Most Endangered Primates 2008-2010. Panamericana Formas e Impresos SA. Bogota.

[5] Munds, R. A., Nekaris, K. A. I., Ford, S. M. 2013. Taxonomy of the Bornean Slow Loris, With New Species Nycticebus kayan (Primates, Lorisidae). American Journal of Primatology, 75:46-56.

[6] Nekaris, K. A. I., and Bearder, S. K. 2007. The strepsirrhine primates of Asia and Mainland Africa: diversity shrouded in darkness. pp: 24-45 in Campbell, C; Fuentes, A; MacKinnon, K; Panger, M dan Bearder, SK, editors. Primates in Perspective. Oxford University Press. Oxford.

[7] CITES. 2006. Convention on International Trade in Endangered Species of Wild Fauna and Flora. Genewa: CITES.

[8] Nursahid, R., Purnama, dan Asep, R. 2007. Perdagangan Kukang (Nycticebus coucang) di Indonesia. http://www.profauna.org. Diakses tanggal 23 Maret 2018.

[9] Wirdateti, Setyorini, L. E., Suparno, dan Handayani, T. H. 2005. Pakan dan Habitat Kukang (Nycticebus coucang) di Hutan Lindung Perkampungan Baduy, Rangkasbitung, Banten selatan. Biodiversitas 6 (1): 45-49

[10] Winarti I. 2003. Distribusi dan Struktur Vegetasi Habitat Kukang (Nycticebus coucang Boddaert, 1785) di Desa Marga Mekar, Kecamatan Sumedang Selatan, Sumedang, Jawa Barat. Skripsi. Bandung: Universitas Padjadjaran.

[11] Adimihardja K. 1992. Kasepuhan yang Tumbuh di Atas yang Luruh: Pengelolaan Lingkungan secara Tradisional di Kawasan Gunung Halimun Jawa Barat. Bandung: Tarsito.

[12] Atmoko, S. S. U., dan M. Arif, R. 2012. Panduan survei sarang orangutan. Forum orangutan Indonesia dan Universitas Nasional. Jakarta

[13] Winarti, I. 2011. Habitat, populasi dan sebaran kukang jawa (Nycticebus javanicus Geoffroy 1812) di talun Tasikmalaya dan Ciamis, Jawa Barat. Tesis. Bogor: Institut Pertanian Bogor.

[14] Alikodra, H.S. 2010. Teknik Pengelolaan Satwaliar. Buku. PT Penerbit IPB Press. Bogor. 368 p.

[15] Tobing, I. S. L. Pengaruh Perbedaan Kualitas Habitat Terhadap Perilaku dan Populasi Primata di Kawasan Cikaniki, Taman Nasional Gunung Halimun, Jawa Barat. Bogor: Institut Pertanian Bogor. 1999. 
[16] Parikesit et al. 2004. Kebon tatangkalan: a disappearing agroforest in the Upper
Citarum Watershed, West Java, Indonesia. Agroforest Syst 63:171-18. 